\title{
O trabalho com gramática nos anos iniciais do ensino fundamental
}

\author{
Ana Luzia Videira Parisotto \\ Universidade Estadual Paulista "Júlio de Mesquita Filho" (UNESP), \\ Presidente Prudente, São Paulo, Brasil \\ analu.videira@uol.com.br
}

DOI: http://dx.doi.org/10.21165/el.v46i2.1627

\begin{abstract}
Resumo
Este artigo traz os resultados oriundos de uma pesquisa maior, financiada pelo $\mathrm{CNPq}$, que tem como objetivo suscitar a reflexão sobre formação docente e ensino de língua materna, a fim de compreender as dificuldades enfrentadas cotidianamente pelo professor e quais as contribuições possíveis para a superação do fracasso escolar. É uma pesquisa de base qualitativa, tendo como sujeitos professores de 22 escolas de ensino fundamental do município de Presidente Prudente. O recorte estabelecido para este artigo será o de apresentar os dados relativos ao ensino de gramática. Os resultados apontam que há necessidade de que os professores observem que o ensino de gramática pode acontecer por meio de atividades de leitura, de escrita ou de refacção de textos produzidos por seus alunos do ensino fundamental.
\end{abstract}

Palavras-chave: ensino de língua materna; ensino de gramática; formação docente.

\section{Grammar teaching in the first years of elementary school}

\begin{abstract}
This article presents the results derived from a larger, ongoing CNPq-funded research project that aims to raise the debate on teacher education and mother tongue teaching, in order to understand the difficulties daily faced by schoolteachers and make contributions to overcome school failure. Teachers from twenty-two elementary schools in Presidente Prudente, Brazil, participate in this qualitative research. This article focuses on the data related to grammar teaching. The results indicate that schoolteachers need to be aware that the teaching of grammar can also happen through activities of reading, writing or rewriting texts produced by their elementary school students.
\end{abstract}

Keywords: mother tongue teaching; grammar teaching; teacher education.

\section{Introdução}

Este artigo deriva de uma pesquisa mais ampla, financiada pelo Conselho de Desenvolvimento Científico e Tecnológico (CNPq), cujo objetivo foi suscitar a reflexão sobre formação docente e ensino de língua materna, no sentido de compreender as dificuldades enfrentadas cotidianamente pelo professor e quais as contribuições possíveis para a superação do fracasso escolar. Foi realizada no município de Presidente Prudente e contou com a participação de 158 professores de 22 escolas de ensino fundamental.

A delimitação que estabelecemos para este artigo refere-se ao ensino de gramática, enfatizando as práticas desenvolvidas por professores para ensiná-la nas aulas de língua materna, nos anos iniciais da educação fundamental. Sabemos que estudos sobre concepções e ensino de gramática não são recentes e que, a partir deles, muito já se falou 
sobre a necessidade de se desfazer a crença de que a aprendizagem de uma língua está vinculada única e exclusivamente ao aprendizado de regras gramaticais (POSSENTI, 2012; PERINI, 2000; NEVES, 2013; MATTOS E SILVA, 2004). Todavia, a discussão de tal temática continua vigente, já que o professor de língua materna ainda considera que ensinar a língua é a mesma coisa que ensinar gramática ou que só se trabalha gramática a partir de regras prescritivas.

$\mathrm{Na}$ primeira seção deste artigo, serão apresentados os pressupostos teóricos relacionados ao ensino de língua materna e à formação docente; na segunda seção, traremos o percurso metodológico para obtenção e análise dos dados; finalmente, na terceira seção, procederemos à exposição e discussão dos dados categorizados em função das respostas emitidas pelos professores à questão: como você trabalha com gramática?

\section{Ensino de língua materna e formação docente: correlações necessárias}

Possenti (2012) afirma que a discussão sobre o ensino da gramática na escola pode revelar diferentes orientações didáticas, ou seja, é possível ensinar a partir do uso observado ou a partir de regras.

O autor acrescenta ainda que o primeiro passo para a discussão do ensino da gramática deve pautar-se na definição de gramática como "conjunto de regras": 1) conjunto de regras que devem ser seguidas; 2) conjunto de regras que são seguidas; 3 ) conjunto de regras que o falante da língua domina.

O professor, de um modo geral, conhece e aplica mais em suas aulas a primeira definição de gramática, ou seja, "conjunto de regras que devem ser seguidas", na medida em que seu objetivo é fazer com que os alunos falem e escrevam corretamente a variedade padrão. Em contrapartida, Possenti $(2012$, p. 82) preceitua que:

A aceitação de que o objetivo prioritário da escola é permitir a aquisição da gramática no sentido 3) compromete a escola com uma metodologia que passa pela exposição constante do aluno ao maior número possível de experiências lingüísticas na variedade padrão. Trocando em miúdos, prioridade absoluta para a leitura, para a escrita, a narrativa oral, o debate e todas as formas de interpretação (resumo, paráfrase, etc.).

Aos três tipos de gramática apresentados por Possenti (2012), Antunes (2007) elenca mais dois: gramática como disciplina de estudo, com carga horária prevista em separado de outros componentes curriculares e gramática como compêndio descritivonormativo da língua.

Franchi (2006) afirma que as expressões "gramática", "gramatical" e "saber gramática" estão relacionadas com "texto" e com "discurso" e que, portanto, os professores devem retomar esses conceitos. Além disso, assevera que os docentes devem ainda: saber muito bem a gramática da norma culta, compreender a gramática da modalidade de seus alunos, bem como ser capaz de analisar casos apresentados nas diferentes modalidades.

Da mesma forma, Neves (2013) destaca que observar os usos linguísticos pressupõe deixar de lado a análise que busca a homogeneização dos itens da língua, já que tomar a língua em uso como objeto de investigação é aceitar que o uso da linguagem e a produção de texto acontecem nas situações de interação verbal. Nesse sentido, a 
filiação teórica da autora, ou seja, a perspectiva funcionalista da linguagem, permite observar o uso da língua em relação a todo o sistema, o significado em relação à forma linguística e o social em relação às preferências individuais dos falantes. Assim, a estrutura gramatical é analisada dentro de uma situação comunicativa, sem a qual não poderíamos compreender o fato linguístico.

Embora a escola se preocupe com a homogeneidade e com os padrões linguísticos considerados ideais, ressaltamos que nenhuma língua é homogênea e isenta de casos de variação. Muitas vezes, o ensino de gramática sem a consideração de aspectos discursivos pode levar a uma falsa ideia de homogeneidade.

Com relação a um ensino de língua materna mais voltado às práticas de linguagem, Geraldi (1996, p. 63) já enfatizava, na década de 1990, a importância de a sala de aula constituir-se num local de reflexão sobre o "já conhecido" para se aprender o desconhecido e construir novos conhecimentos:

[...] as atividades de reflexão sobre a linguagem (atividades epilinguísticas) são mais fundamentais do que a aplicação de fenômenos sequer compreendidos de uma metalinguagem de análise construída pela reflexão de outros. Aquele que aprendeu a refletir sobre a linguagem é capaz de compreender uma gramática - que nada mais é do que o resultado de uma (longa) reflexão sobre a língua.

Pelo exposto até aqui, começa a delinear-se a necessária correlação entre formação docente e ensino de língua materna. Dessa forma, é importante recuperarmos os dizeres de Marcelo Garcia (1999), ao abordar o conceito de "formação". O autor afirma que existem vários tipos de abordagem desse conceito com possibilidades de correlações diversas, todavia destaca a importância de se conceber o processo de formação como algo contínuo.

O verbo formar-se pressupõe fugir de algo corriqueiro e passivo, de se deixar modelar, para evoluir em direção a algo mais dinâmico cuja característica semântica essencial é colocar-se em movimento, abrir-se a novas possibilidades. No que concerne à formação docente e ao ensino de gramática, isso significa reconsiderar práticas e teorias, manifestando a reflexão que deve existir sobre o fazer docente e o conhecimento construído.

Muitas pesquisas trazem o percurso histórico de concepções estabelecidas entre "professor das primeiras letras" e o professor como "agente letrador" (BORTONIRICARDO, 2010; KLEIMAN, 2012). E é nesse caminhar que se tem marcados os avanços e as tensões no sentido de se atribuir à docência o caráter de profissão. Assim, a formação inicial e continuada de professores é investigada como forma de lançar novos olhares, atentando para as novas demandas da sociedade.

No que diz respeito à formação continuada, Rinaldi e Parisotto (2013, p. 181) afirmam que:

Dada à complexidade da tarefa que se propõe à escola, a formação contínua de seus integrantes é fundamental - em especial a dos professores e dirigentes - de modo que eles também possam ser considerados cidadãos/profissionais de primeira linha, que atendam às exigências que se colocam à população em geral e mesmo as ultrapassem, visto que serão os responsáveis por ensinar aqueles que precisam aprender em novos moldes e sob novas perspectivas. Além do que, é preciso investir igualmente em 
professores que estão em diferentes momentos da carreira, tanto profissionais experientes como iniciantes - que têm, como a literatura da área de formação de professores vem apontando, necessidades formativas diferentes - visto que a tarefa proposta é para a escola como um todo e não para apenas uma parte dos docentes e gestores que ali trabalham.

Tardif (2007) traz uma importante contribuição ao descrever os fundamentos epistemológicos da prática docente, partindo da premissa de que a competência desse profissional integra uma pluralidade de saberes estabelecida em quatro modalidades: saberes de formação profissional, saberes disciplinares, saberes curriculares e saberes de experiência.

Os saberes profissionais dizem respeito ao conjunto de saberes contemplados pelas instituições de formação de professores. São saberes oriundos das ciências da educação em termos de teorias e concepções que possam orientar a prática educativa, portanto, produzidos para serem incorporados à formação profissional do professor. Seriam os saberes pedagógicos que o professor mobilizaria para atender a função da instituição escolar.

Os saberes disciplinares correspondem aos saberes situados nos diversos campos de conhecimento (matemática, literatura, história etc.), emergentes da tradição cultural e dos grupos sociais produtores de saberes. Dizem respeito à definição e seleção, realizadas pela universidade, dos saberes sociais, ou seja, a escolha da matéria-prima a ser trabalhada nos diferentes cursos oferecidos.

Em contrapartida, os saberes curriculares dizem respeito aos aspectos atinentes aos discursos, objetivos, conteúdos e métodos contemplados pela universidade para a operacionalização dos saberes disciplinares. Quando os conteúdos a serem ensinados são escolhidos pelo professor, este saber sofre um conjunto de transformações adaptativas para torná-lo apto a ocupar um lugar entre os objetos de ensino. Trata-se do importante trabalho de preparação didática elaborada em vista da passagem desse objeto para a situação de ensino.

Finalmente, o autor acrescenta os saberes de experiência, fundados no trabalho cotidiano do professor e no conhecimento do seu meio. A competência profissional, segundo Tardif (1999), deve expressar todos esses domínios de saberes, pois deve conhecer sua matéria, sua disciplina e seu programa, deve possuir conhecimentos relativos à pedagogia, sem deixar de desenvolver um saber embasado em sua experiência cotidiana com os alunos.

Além da formação e dos saberes docentes, as políticas educacionais também se destacam como relevantes no ensino de língua materna. No caso específico de nossa pesquisa no município de Presidente Prudente, tornou-se essencial compreender como ocorre o processo de formação continuada dos professores atuantes nos anos iniciais do Ensino Fundamental para que fossem pensadas ações formativas tanto no âmbito do sistema municipal quanto nas escolas e/ou na própria universidade.

O recorte estabelecido para este artigo, como já dito anteriormente, será o de apresentar os dados relativos ao ensino de gramática nos anos iniciais da educação fundamental. Para tanto, foram analisadas as respostas emitidas por 158 docentes. 


\section{Metodologia}

Trata-se de uma pesquisa qualitativa, cujos dados foram obtidos por meio de questionários aplicados a 158 professores, de 22 escolas municipais vinculadas à Secretaria de Educação do Município de Presidente Prudente.

O estudo foi organizado em três fases: na primeira, realizamos a pesquisa documental a fim de identificarmos o desempenho das escolas pesquisadas em avaliações externas como SARESP (Sistema de Avaliação de Rendimento Escolar do Estado de São Paulo) e ANA (Avaliação Nacional da Alfabetização). A partir disso, aplicamos os questionários aos professores das vinte e duas escolas de ensino fundamental I do município de Presidente Prudente que aceitaram participar da pesquisa; na fase 2, iniciamos o processo de organização e de tabulação dos dados; finalmente, na fase 3 , desenvolvemos práticas formativas consideradas pelos professores como eficazes, a partir do levantamento dos questionários.

A investigação pautou-se na abordagem qualitativa de pesquisa que, de acordo com Bogdan e Biklen (1994), apresenta como características essenciais: o ambiente natural como fonte direta de dados; o pesquisador como seu principal instrumento; o fato de os dados coletados serem predominantemente descritivos; a preocupação com o processo ser maior do que com o produto; a consideração pelo pesquisador dos fatos na perspectiva dos participantes; a tendência de os dados serem analisados por meio de um processo indutivo.

Ainda sobre a pesquisa qualitativa, André (2013, p. 97) enfatiza que:

As abordagens qualitativas de pesquisa se fundamentam numa perspectiva que concebe o conhecimento como um processo socialmente construído pelos sujeitos nas suas interações cotidianas, enquanto atuam na realidade, transformando-a e sendo por ela transformados. Assim, o mundo do sujeito, os significados que atribui às suas experiências cotidianas, sua linguagem, suas produções culturais e suas formas de interações sociais constituem os núcleos centrais de preocupação dos pesquisadores. Se a visão de realidade é construída pelos sujeitos, nas interações sociais vivenciadas em seu ambiente de trabalho, de lazer, na família, torna-se fundamental uma aproximação do pesquisador a essas situações.

Os questionários destinados aos docentes foram utilizados para caracterizar o perfil pessoal, profissional e teórico-metodológico do professor que leciona nos anos iniciais do ensino fundamental.

Severino (2008, p. 125) afirma que o questionário pode ser descrito como:

Conjunto de questões, sistematicamente articuladas, que se destinam a levantar informações escritas por parte dos sujeitos pesquisados, com vistas a conhecer a opinião dos mesmos sobre os assuntos em estudo. As questões devem ser pertinentes ao objeto e claramente formuladas, de modo a serem bem compreendidas pelos sujeitos. As questões devem ser objetivas, de modo a suscitar respostas igualmente objetivas, evitando provocar dúvidas, ambiguidades e respostas lacônicas. Podem ser questões fechadas ou questões abertas. No primeiro caso, as respostas serão colhidas dentre as opções predefinidas pelo pesquisador; no segundo, o sujeito pode elaborar as respostas, com suas próprias palavras, a partir de sua elaboração pessoal. 
No caso deste artigo, nosso interesse diz respeito à forma como os professores dizem trabalhar com a gramática no ensino fundamental I. Assim analisaremos uma questão classificada como aberta, por conter respostas de elaboração pessoal do professor.

Os dados foram tabulados e analisados à luz do referencial teórico voltado para o ensino de gramática e formação docente (GERALDI, 2013; IMBERNÓN, 2005; TARDIF, 2008; FRANCHI, 2006; NEVES, 2001; ANTUNES, 2014.)

A fim de observarmos a recomendação do Comitê de Ética em Pesquisa, os sujeitos foram identificados por escola como P1, P2 e assim por diante. Além disso, o nome das escolas foi substituído por nomes de flores.

\section{O que revelam os professores sobre o ensino de gramática na etapa pesquisada}

Para a análise dos dados, foi utilizada uma escala de notas: de 0 a 1,9 (respostas consideradas péssimas), de 2,0 a 3,9 (respostas ruins), de 4,0 a 5,9 (respostas regulares), de 6,0 a 7,9 (respostas boas) e, finalmente, de 8,0 a 10,0 (respostas excelentes). As respostas classificadas como ruins ou péssimas foram aquelas que desconsideravam uma proposta de trabalho textual-discursivo; já aquelas classificadas como regulares, boas e excelentes apresentaram uma maior possibilidade de trabalho com aspectos textuaisdiscursivos. Dessa forma, o Gráfico 1, a seguir, traz os resultados a serem discutidos:

Gráfico 1. Avaliação das respostas emitidas pelos docentes

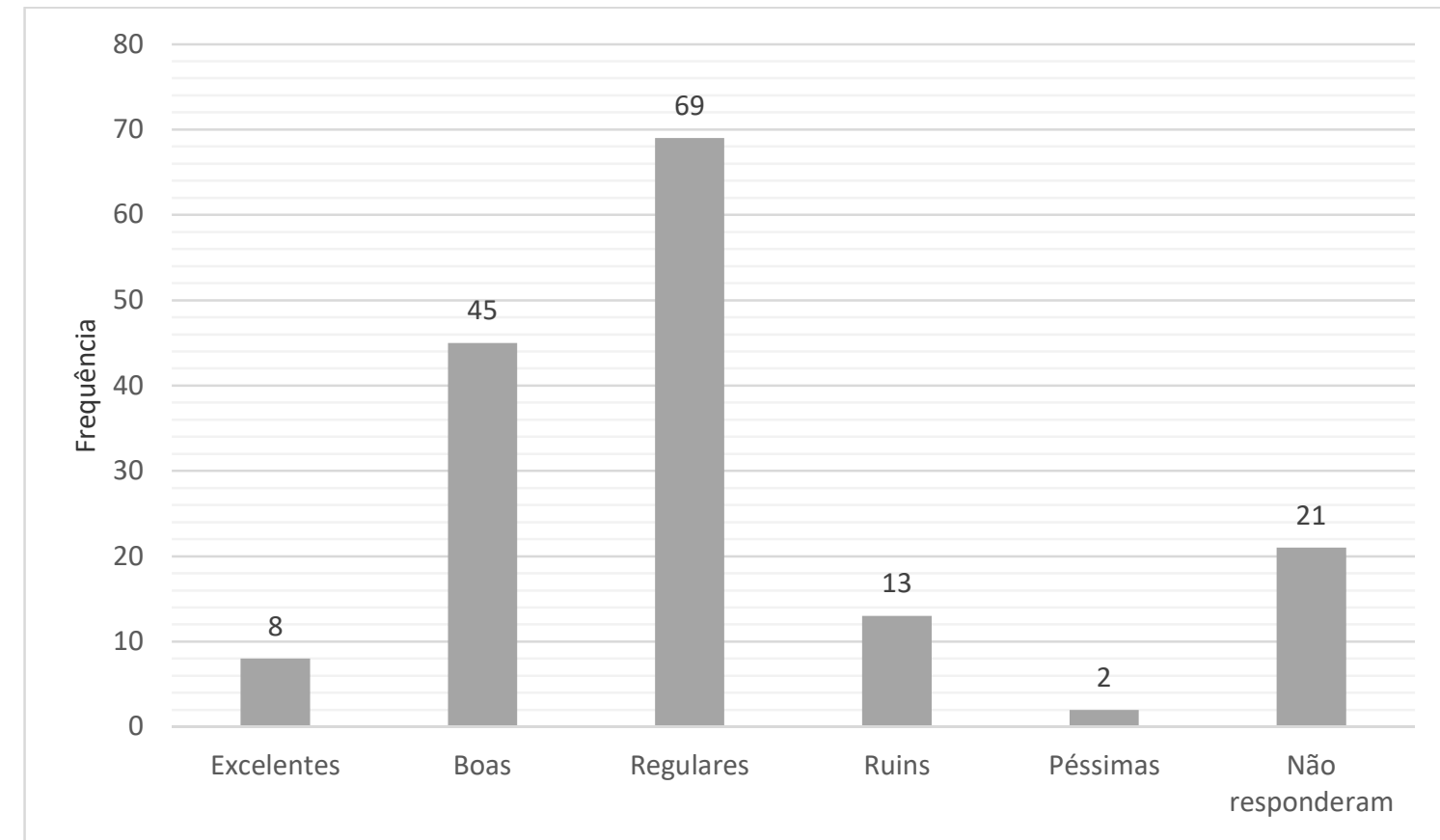

Conforme se observa no Gráfico 1, houve oito respostas consideradas excelentes, 45 respostas apreciadas como boas, 69 respostas julgadas como regulares, 13 respostas conceituadas como ruins e duas consideradas péssimas. Dos 158 professores sujeitos da pesquisa, 21 não responderam à questão sobre ensino de gramática. docentes.

Destacaremos, a seguir, a título de exemplo, algumas respostas apresentadas pelos 
a) Respostas consideradas excelentes:

(1) Trabalho com um $1^{\circ}$ ano que está em fase inicial da alfabetização, por esse motivo ainda não realizo esse trabalho. Mas, muitas vezes, refletimos sobre gramática quando produzimos textos orais. (P1, Magnólia).

(2) É refletir sobre gramática na construção de textos, na leitura. (P4, Dália).

As respostas mencionadas abordam aspectos importantes relacionados ao ensino de gramática nos anos iniciais. O P1, da escola Magnólia, afirma não trabalhar com gramática, pois leciona no primeiro ano. Todavia, reflete sobre gramática, ao produzir textos orais com as crianças. Nesse caso, avaliamos a resposta como excelente por inferirmos que o docente não valoriza o ensino da metalinguagem na fase inicial de aquisição da escrita. Já a resposta de P4, escola Dália, destaca a possibilidade de se trabalhar a gramática na construção de textos e na leitura. A partir dessas respostas, é possível observar que esses professores, possivelmente, já internalizaram que o conhecimento descritivo da língua sozinho não traz grandes contribuições para formação de alunos leitores e produtores de textos (GERALDI, 1996).

b) Respostas consideradas boas:

(3) Trabalho a partir da análise de textos. Faço o estudo da gramática do texto. (P5, Alecrim).

(4) Por meio da realização de atividades, explicação oral e demonstrativa, na reescrita de produções dos alunos. (P2, Hortência).

Os exemplos (3) e (4) enfatizam o trabalho com gramática a partir de textos. O P2, da escola Hortênsia, menciona o trabalho com gramática nas atividades de reescrita das produções dos alunos. Verificamos, de acordo com os exemplos, a valorização do texto como unidade de análise; em contrapartida, Antunes (2014, p. 41) chama nossa atenção para o fato de que:

No meio pedagógico, é comum a referência a uma certa "gramática contextualizada", expressão que se impôs, por um lado, para designar a tentativa dos professores de centrar o ensino de gramática em textos e, por outro lado, para caracterizar a fuga ao estudo da gramática centrada em análise de prescrições e frases soltas.

Houve muitas respostas em que os docentes simplesmente escreveram que trabalhavam com "gramática contextualizada". Nessas ocorrências, acreditamos que as respostas foram ao encontro do preconizado por Antunes (2014). Isso pôde ser constatado em outros encontros que mantivemos com os docentes, por ocasião do oferecimento de oficinas de formação que já estavam previstas no cronograma inicial do projeto de pesquisa. Vale ressaltar que os conteúdos a serem trabalhados nas oficinas foram indicados pelos sujeitos da pesquisa, já que entendemos que os processos formativos devem atender às demandas de formação apresentadas pelos professores (IMBERNÓN, 2005). Nesses momentos, verificamos claramente o que entendiam por "gramática contextualizada". Para a maioria dos docentes, trabalhar com gramática de forma contextualizada significa retirar ou formular exercícios gramaticais a partir de um texto, geralmente o que está presente no livro didático. 
c) Respostas consideradas regulares:

(5) Atividades vinculadas aos textos presentes no livro didático. (P6, Margarida).

(6) Trabalhada no texto que após ser lido e interpretado, riscando com cores diferentes o substantivo, adjetivo, palavras com ações, derivadas, no plural, singular etc. (P4, Margarida).

Os exemplos (5) e (6) ilustram adequadamente o que foi mais frequente nas respostas dos docentes. Eles geralmente mencionam que trabalham com atividades presentes em materiais didáticos, sem omitir o fato de que são atividades relacionadas a textos. O P4, da escola Margarida, exemplifica uma atividade voltada para o estudo morfológico das palavras do texto que, segundo a docente, é lido e interpretado. Nesse sentido, Neves (2013, p. 15) assevera que:

[...] a explicitação de uso de uma língua particular historicamente inserida, feita com base em reflexão sobre dados representa a explicitação do próprio funcionamento da linguagem. Isso exclui qualquer atividade de encaixamento em moldes pré-fabricados, tanto os que constituem uma organização de entidades metalinguísticas alheias aos processos reais de funcionamento quanto os que representam modelos para submissão escrita a normas linguísticas sem legitimidade instituídas.

d) Respostas consideradas ruins:

(7) Partindo de um texto, tirar atividade do mesmo, exercícios de fixação. (P3, Camélia).

(8) Trabalhar os conceitos e propor atividades de fixação. (P3, Gérbera).

A partir da análise dos dados, 13 respostas foram classificadas como ruins, ou seja, são respostas que revelam práticas inadequadas para o ensino de gramática. $\mathrm{O}$ exemplo (7) leva-nos a pensar que o professor trabalha somente o texto como pretexto para ensinar gramática. Sobre essa prática, Lajolo (1982), ao refletir sobre o ensino da leitura, na década de 1980 já afirmava que, muitas vezes, o professor utiliza o texto como pretexto para memorização de vocabulário e regras gramaticais. Já o exemplo (8) deixa claro que o professor valoriza a metalinguagem e as atividades mecânicas de fixação de regras. O que reforça o entendimento de "gramática como conjunto de regras que devem ser seguidas" (POSSENTI, 2012).

e) Respostas consideradas péssimas

Interpretações, palavras. (P3, Petúnia).

(10) Estudo de conceitos e regras para avaliação. (P4, Acácia).

Foram somente duas as respostas consideradas péssimas. Embora o professor tenha respondido à questão que lhe foi indagada, no exemplo (9), não houve uma explicitação adequada de como costuma trabalhar com gramática. Em contrapartida, o exemplo (10) ilustra nitidamente a valorização do ensino de conceitos e regras com vistas a uma avaliação. Neves (2013) afirma que a valorização da língua em uso pressupõe que a avaliação deva considerar o domínio discursivo, prevendo a interação verbal como atividade estruturada e cooperativa. 


\section{Considerações finais}

Os resultados deste estudo permitem-nos dizer que os professores, de acordo com o explicitado nas respostas dos questionários, trabalham com a gramática por meio de textos, que, na maioria das vezes, são oriundos de materiais didáticos. E fica subjacente em suas respostas que a maioria considera gramática como "conjunto de regras que devem ser seguidas". Além disso, possuem um conceito equivocado do que seja "gramática contextualizada", pois acreditam que, se as atividades forem retiradas do texto, já houve uma contextualização do conteúdo a ser estudado. Mesmo quando são atividades mecânicas que envolvem somente, por exemplo, classificar palavras do texto.

As respostas mais adequadas foram aquelas em que os docentes mencionaram um ensino que valoriza a reflexão, as atividades epilinguísticas durante os processos de reescrita de textos e a construção de regras. Em contrapartida, as consideradas inadequadas foram as que valorizaram o uso da metalinguagem, o texto como pretexto para se ensinar gramática e a memorização de regras para resolução de exercícios avaliativos. Tais práticas desconsideram o aluno como sujeito discursivo, pois não buscam propiciar a reflexão sobre conhecimentos linguísticos que sejam pertinentes aos anos iniciais do ensino fundamental.

Em linhas gerais, ainda é necessário o professor compreender que o trabalho com gramática envolve as regras que regem as expressões linguísticas, mas também as que dizem respeito ao processo de interação verbal. É importante que sejam trabalhados textos concretos sempre no nível textual-discursivo da língua. Nesse sentido, as produções textuais dos alunos continuam sendo muito adequadas para o ensino de gramática, na medida em que trazem todo o repertório do "já conhecido" para sinalizar "o desconhecido" que precisa ser aprendido.

A partir do exposto, observamos que o processo de formação continuada de professores pode constituir-se num significativo momento para se devolver a palavra aos sujeitos, a fim de que, num processo dialógico, se tornem responsáveis por sua formação, enfatizando o seu contexto de trabalho. O conhecimento da língua materna é fundamental para o docente dos anos iniciais do ensino fundamental exercer com proficiência a sua função de ensinar as crianças a ler e a produzir textos. Dessa maneira, é possível ir se transformando em professor ao longo do caminho, ou seja, ele desempenha a sua profissão com o que aprendeu nos processos de formação inicial e continuada e vai se construindo, ao incorporar e refletir sobre a pluralidade de saberes, atitudes e metodologias de ensino.

\section{REFERÊNCIAS}

ANDRÉ, M. E. D. A. de. O que é um estudo de caso qualitativo em Educação? Revista da FAEEBA - Educação e Contemporaneidade, Salvador, v. 22, n. 40, p. 95-103, jul./dez. 2013.

ANTUNES, I. Muito além da gramática: por um ensino de línguas sem pedras no caminho. São Paulo: Parábola Editorial, 2007.

Gramática contextualizada: limpando o 'pó das ideias simples'. São Paulo: Parábola Editorial, 2014. 
BOGDAN, R.; BIKLEN, S. Investigação qualitativa em educação: uma introdução à teoria e aos métodos. Porto: Porto Editora, 1994.

BORTONI-RICARDO, S. M.; MACHADO, V. R.; CASTANHEIRA, S. F. Formação do professor como agente letrador. São Paulo: Contexto, 2010.

FRANCHI, C. Mas o que é mesmo "gramática"? In: POSSENTI, S. (Org.). Mas o que é mesmo "gramática"? São Paulo: Parábola Editorial, 2006.

GERALDI, J. W. Linguagem e ensino: exercícios de militância e divulgação. Campinas: Mercado de Letras, 1996.

Portos de passagem. 5. ed. São Paulo: Martins Fontes, 2013.

IMBERNÓN, F. Formação docente e profissional: formar-se para a mudança e a incerteza. São Paulo: Cortez, 2005.

KLEIMAN, A. B. Os significados do letramento: uma nova perspectiva sobre a prática social da escrita. 2. ed. Campinas: Mercado de Letras, 2012.

LAJOLO, M. O texto não é pretexto. In: ZILBERMAN, R. (Org.). Leitura em crise na escola: as alternativas do professor. Porto Alegre: mercado Aberto, 1982.

MARCELO GARCIA, C. Formação de professores: para uma mudança educativa. Porto: Porto Ed., 1999.

MATTOS E SILVA, R. V. "O português são dois...": novas fronteiras, velhos problemas. São Paulo: Parábola Editorial, 2004.

NEVES, M. H. M. Texto e gramática. 2. ed. São Paulo: Contexto, 2013.

. Gramática na escola. 5. ed. São Paulo: Contexto, 2001.

PERINI, M. A. Sofrendo a gramática. São Paulo: Ática, 2000.

POSSENTI, S. Por que (não) ensinar gramática na escola. 2. ed. Campinas: São Paulo: Mercado de Letras, 2012.

RINALDI, R. P.; PARISOTTO, A. L. V. Desenvolvimento profissional de professores e formadores da educação básica: primeiras aproximações. Revista Teias, v. 14, n. 31, p. 180-202, mai./ago. 2013.

SEVERINO, A. J. Metodologia do trabalho científico. São Paulo: Cortez, 2008.

TARDIF, M. Saberes profissionais dos professores e conhecimentos universitários. Rio de Janeiro: PUC, 1999. . Saberes docentes e formação profissional. 8. ed. Petrópolis: Vozes, 2007.

Recebido em: 29/08/2016

Aprovado em: 29/11/2016 